FINANÇAS 


\section{OPORTUNISMO COMO DETERMINANTE DA ESTRUTURA DE CAPITAL: UM ESTUDO DE CASO EM NANOTECNOLOGIA}

OPPORTUNISM AS DETERMIMANT OF CAPITAL STRUCTURE: A CASE STUDY IN NANOTECHNOLOGY

Milena de Cassia Rocha

Universidade Federal de Minas Gerais

Márcio Gonçalves

Universidade Federal de Minas Gerais

Francisco Barbosa

Universidade Federal de Minas Gerais
Data de submissão: | | abr. 20 |6. Data de aprovação:

28 jan. 2017. Sistema de avaliação: Double blind review. Universidade FUMEC / FACE. Prof. Dr. Henrique Cordeiro Martins. Prof. Dr. Cid Gonçalves Filho.

\section{RESUMO}

A discussão sobre os determinantes da estrutura de capital é algo que vem sendo realizado há algum tempo. Contudo, é observado uma lacuna a respeito do tema em empresas de nanotecnologia, assim como trabalhos que enfoquem a ideia do oportunismo como determinante da estrutura de capital. Sendo assim, o presente artigo traz uma discussão sobre a ideia do oportunismo como determinante da estrutura de capital em empresas de nanotecnologia no Brasil. Para tanto, foi realizado um estudo de caso abordando aspectos ligados a estrutura de capital adotada, a verificação da utilização de determinadas teorias sobre o tema e a relevância de algumas fontes. Foi observado que a empresa analisada utiliza a ideia do oportunismo como determinante da estrutura de capital devido aos fatores relacionados ao custo das fontes e as exigências por parte dos credores. Assim, em momentos em que os custos e as exigências são aceitáveis, para a empresa, se opta por tais fontes.

PALAVRA-CHAVE

Estrutura de Capital. Ideia do Oportunismo. Nanotecnologia. 


\section{ABSTRACT}

Discussion about determinants of capital structure has been carried on for some time. However, it has been observed a gap on studies of nanotechnology companies, and articles that focuses on the idea of opportunism as a determinant of capital structure, as well. Therefore, this article provides a discussion about the idea of opportunism as a determinant of capital structure in nanotechnology companies in Brazil. So, it was conducted a case study approaching aspects of the adopted capital structure, there was the verification of certain theories about the theme said some sources relevance.

It was observed that the company uses the company uses the idea of opportunism as a determinant of its capital structure. This occurs due to factor related to the cost of sources and creditors requirements. Thus, the company chooses the sources when the costs and requirements are acceptable.

\section{KEYWORD}

Capital Structure. Opportunism. Nanotechnology.

\section{INTRODUÇÃO}

A estrutura de capital é compreendida como sendo a forma pela qual uma empresa se financia, ou seja, refere-se ao modo como as fontes de recursos financeiros (próprio ou de terceiros) estão distribuídas. Desde Duran (1952), até os dias atuais, vários pesquisadores buscam encontrar uma estrutura ótima de capital, assim como seus determinantes.

Modigliani e Miller (1958) admitiram que estrutura de capital não influência no valor da empresa. Jensen e Meckling (1976) demonstraram que a estrutura ótima de capital é definida considerando o custo de agência. Já Scott (1972) e DeAngelo e Mansulis (1980) defenderam que a estrutura de capital ótima resulta no equilíbrio entre os benefícios fiscais e os custos potenciais de falência associados ao endividamento.

Contudo, para Myers (1984, p. 575) "Como as empresas escolhem sua estrutura de capital? Novamente, a resposta é nós não sabemos. [...] Nós sabemos muito pouco sobre estrutura de capital. Não sabemos como as empresas escolhem dívida, capital próprio [...]”.

Não existe ainda uma base teórica sólida que explique de forma definitiva as estruturas de financiamento utilizadas pelas empresas (SILVA, 2009). O que se tem são teorias e ideias originadas de pesquisas empíricas, dentre elas pode-se citar: teoria tradicional, trade off, teoria de agência, pecking order, e a ideia do oportunismo.

Esta última, objeto de enfoque neste artigo, surgiu com o intuito de explicar o movimento que acontece em alguns países onde se observa uma escolha pelas fontes que apresentam um menor custo, sem levar em consideração qualquer hierarquia ou definição de uma estrutura meta. Os trabalhos de Eid Júnior (1996), Graham e Harvey (200I), Baker, Greenwood e Wurgler (2002), Gimenes, Opazo e Gimenes (2003), e Santos, Pimenta Junior e Coccini 
(2009) trazem em suas contribuições evidências da ideia do oportunismo como determinante da estrutura de capital.

Os trabalhos mencionados analisaram empresas em diversos segmentos, contudo, apenas, Gimenes, Opazo e Gimenes (2003) focaram em uma amostra de cooperativas agropecuárias. $O$ delineamento do segmento é observado como sendo algo que contribui para uma melhor compreensão sobre o tema, uma vez que o cenário em que tais empresas se encontram possuem características que influenciam na escolha da estrutura de capital.

Caso este observado na indústria de nanotecnologia no Brasil.As empresas que fazem parte deste mercado surgiram com a proposta de oferecer produtos com maior qualidade, por meio da inovação em processos. Consideradas empresas de base tecnológica (EBTs) e criadas, em sua maioria, por pesquisadores, exigem altos investimentos em recursos humanos (uma vez que precisam contar com colaboradores de alta qualificação), em infraestrutura e em equipamentos específicos e customizados. Jones e Jayawarna (2010) e Bosse (2009) acrescentam que as EBTs, ainda, apresentam inexistência de histórico de receita, de demonstrações financeiras, assim como a falta de garantias reais que poderiam ser oferecidas em contrapartida na aquisição de recurso financeiro.

Diante do exposto, questiona-se qual seria a estrutura de capital em um cenário como o apresentado, assim como o determinante da mesma.

A presente pesquisa se justifica por apresentar um estudo que aborda aspectos relacionados ao determinante de estrutura de capital no Brasil em uma empresa Ltda do segmento de nanotecnologia, buscan- do apresentar a partir de dados primários informações relevantes para o desenvolvimento do conhecimento sobre ao tema.

\section{TEORIAS DE ESTRUTURA DE CAPITAL Teorias Clássicas}

Os estudos referentes à estrutura de capital tiveram início com a Teoria Tradicional de Duran (1952). Tal teoria defende que a melhor estrutura de capital é dada pelo valor de mercado da empresa alterado em função do maior grau de alavancagem financeira. Ainda de acordo com a teoria tradicional, o valor de uma empresa não é independe da composição entre capital próprio e capital de terceiros, demonstrando assim que a estrutura de capital é relevante para a definição do valor da empresa. Outro ponto importante está ligado ao fato de que a teoria tradicional sustenta a hipótese de que a empresa pode aumentar o seu valor utilizando em maior grau os recursos de terceiros (DURAN, 1952).

A abordagem da teoria tradicional manteve-se até que Modigliani e Miller (1958) desenvolverem 0 trabalho The Cost of Capital, Corporation Finance, and Theory of Investment que trouxe outra visão para a discussão sobre estrutura de capital.Visto que, para Modigliani e Miller (1958), a estrutura de capital não afeta 0 valor da empresa, em outras palavras, não existe estrutura melhor ou pior para os acionistas.

Em estudos posteriores, Modigliani e Miller (196I) concluíram que o valor da empresa não possui dependência com a política de dividendos adotada. A política de investimentos seria determinada somente pela expectativa de fluxos de caixa futuros. 
O efeito dos impostos foi reconhecido por Modigliani e Miller (1963), o que levou a conclusão de que com a adição dos impostos não se pode mais dizer que o valor de uma empresa alavancada é igual ao valor de uma empresa não-alavancada, e que o custo de capital próprio aumenta com o endividamento da empresa visto que 0 risco também sofre aumento com a alavancagem. Vale ressaltar que a taxa de retorno do capital próprio ainda varia conforme $o$ nível de endividamento da empresa, porém existe um fator de redução.

Após estas discussões, Miller (1977) retoma o estudo referente à estrutura de capital e impostos tendo como ponto central o efeito fiscal da dívida. $O$ autor afirma que os juros que a empresa paga se são dedutíveis no imposto de renda por um lado, por outro também precisa ser incluída uma provisão referente ao imposto que o dono do título da dívida deverá pagar sobre a receita de juros, informando que as empresas deverão pagar um prêmio para compensar a taxação dos investidores, aumentando o custo da dívida. Assim, define-se que um melhor grau de alavancagem só existe em determinados níveis agregados de todas as empresas, concluindo que não se pode definir uma estrutura de capital apenas para uma empresa (MILLER, 1977).

Os trabalhos mencionados fizeram com que várias discussões sobre o tema surgissem, o que levou a construção de novas teorias sobre a estrutura de capital das empresas. Dentre elas, a teoria de agência onde os potenciais conflitos de interesses entre investidores internos e externos é o determinante da estrutura ótima e contrabalança custos de agência com outros custos financeiros (JENSEN; MECKLING, 1976).

Outra teoria que emergiu diante as dis- cussões sobre estrutura de capital foi a de trade-off. De acordo com tal teoria, a empresa escolhe uma estrutura meta com base no índice de endividamento desejado que maximize o valor da firma, minimizando os custos de imperfeição do mercado prevalecente, como impostos, custos de falência e custos de agência (KJELLMAN; HANSÉN, 1995).

Quanto a teoria pecking order, também desenvolvida em meio as discussões sobre o tema, defende que os administradores das empresas estabelecem uma ordem de preferência entre os recursos passíveis de utilização. Em primeiro lugar, recursos que foram gerados internamente; em segundo lugar, recursos por meio de novas dívidas e, por fim recursos por meio do lançamento de novas ações (MYERS; MAJLUF, 1984).

\section{Teoria do Oportunismo}

Nos últimos anos, surgiu uma nova abordagem que busca analisar a relação do impacto de mercados ineficientes e a estrutura de capital. De acordo com Ritter (2002), as janelas de oportunidade (termo usado para referenciar os períodos de flutuação nos preços em que as ações estão sobrevalorizadas pelo mercado) são consequências das ineficiências do mercado de capitais, modificando assim, o custo relativo das diversas fontes de recursos a que a empresa venha recorrer. Assim, o administrador tende a optar pela fonte que seja economicamente mais vantajosa no momento da obtenção dos recursos. Não existe a preocupação em seguir uma hierarquia de fontes de recursos, assim como de manter o nível de endividamento ótimo.

A ideia do oportunismo vem do comportamento humano. Nos quatro pressupostos comportamentais envolvidos em uma transação, sugeridos porWilliamson (1979), dois 
deles mencionam o oportunismo. No primeiro, o oportunismo é um conceito central dos custos de transação e no segundo o oportunismo é importante para atividades econômicas cujas transações demandem investimentos específicos em recursos humanos e de capital. Para Williamson (1979), o oportunismo é visto como sendo uma busca de interesses próprios de forma enganosa, isto porque a Teoria da Economia dos Custos de Transação tem como pressuposto que os agentes econômicos envolvidos em uma transação busquem maximizar seus retornos, às vezes por meio de comportamentos oportunistas.

Ao transpor a ideia do oportunismo para a os estudos em estrutura de capital, Eid Jr. (1996) adota que tal conceito está ligado ao fato de que as empresas realizam a captação de recursos na medida em que surgem boas oportunidades, ou seja, a escolha das fontes de recursos segue uma hierarquia de vantagens econômicas, onde, recursos com menores custos serão utilizados em primeiro lugar, recorrendo à outras alternativas quando estes forem plenamente aproveitados, diferente das teorias expostas anteriormente.

As pesquisas empíricas sobre o tema analisam o oportunismo de duas formas. A primeira avalia seu impacto na estrutura de capital, em que a empresa possui vantagens de flutuações temporárias no preço da ação para emitir e recomprá-la a um custo vantajoso, ou seja, nos momentos de flutuações, o uso de capital próprio se torna mais atraente do que o capital de terceiros. Na segunda forma, caso as taxas de juros estejam mais atraentes, a empresa se financia com recursos de terceiros, buscando se beneficiar das janelas de oportunidades nas captações de recursos ex- terno, ou antecipa possíveis melhoras em sua avaliação creditícia (rating) e recorre a dívidas de curto prazo que o refletirão rapidamente no custo de capital (GRAHAM; HARVEY, 200I; BAKER; GREENWOOD; WURGLER, 2002; RITTER, 2002).

A Figura I apresenta uma hierarquia de captação segundo a abordagem do oportunismo, de acordo com Ritter (2002).

Os estudos empíricos sobre o tema têm sido desenvolvidos tanto no Brasil quanto em outros países. No cenário internacional Baker eWurgler (2002) concluíram que os administradores buscam emitir ações quando o valor contábil da empresa está abaixo do seu valor de mercado, demonstrando que tais gestores são oportunistas em suas decisões de financiamento. Graham e Harvey (200I) também apresentaram evidências que comprovam o oportunismo no momento de definir a estrutura de capital. De acordo com o estudo realizado pelos autores, $46 \%$ dos pesquisados admitiram que se endividam em momentos que a taxa de juros lhes parece atrativa.

Pinegar e Wilbricht (1989), em um estudo sobre estrutura de capital, ao analisarem quais fatores as empresas julgam mais importantes na tomada de decisão sobre financiamento, verificaram que $76,7 \%$ dos entrevistados consideraram o fator "garantia de sobrevivência em longo prazo" o mais importante na definição da estrutura de capital das empresas. Tal estudo não faz menção a teoria do oportunismo, contudo ao se escolher fontes que proporcionam a sobrevivência do negócio pode se inferir que os gestores estão buscando oportunidades que favoreçam a sustentabilidade do negócio, abandonado hierarquias definidas previamente sem uma análise do cenário em que se encontram. 


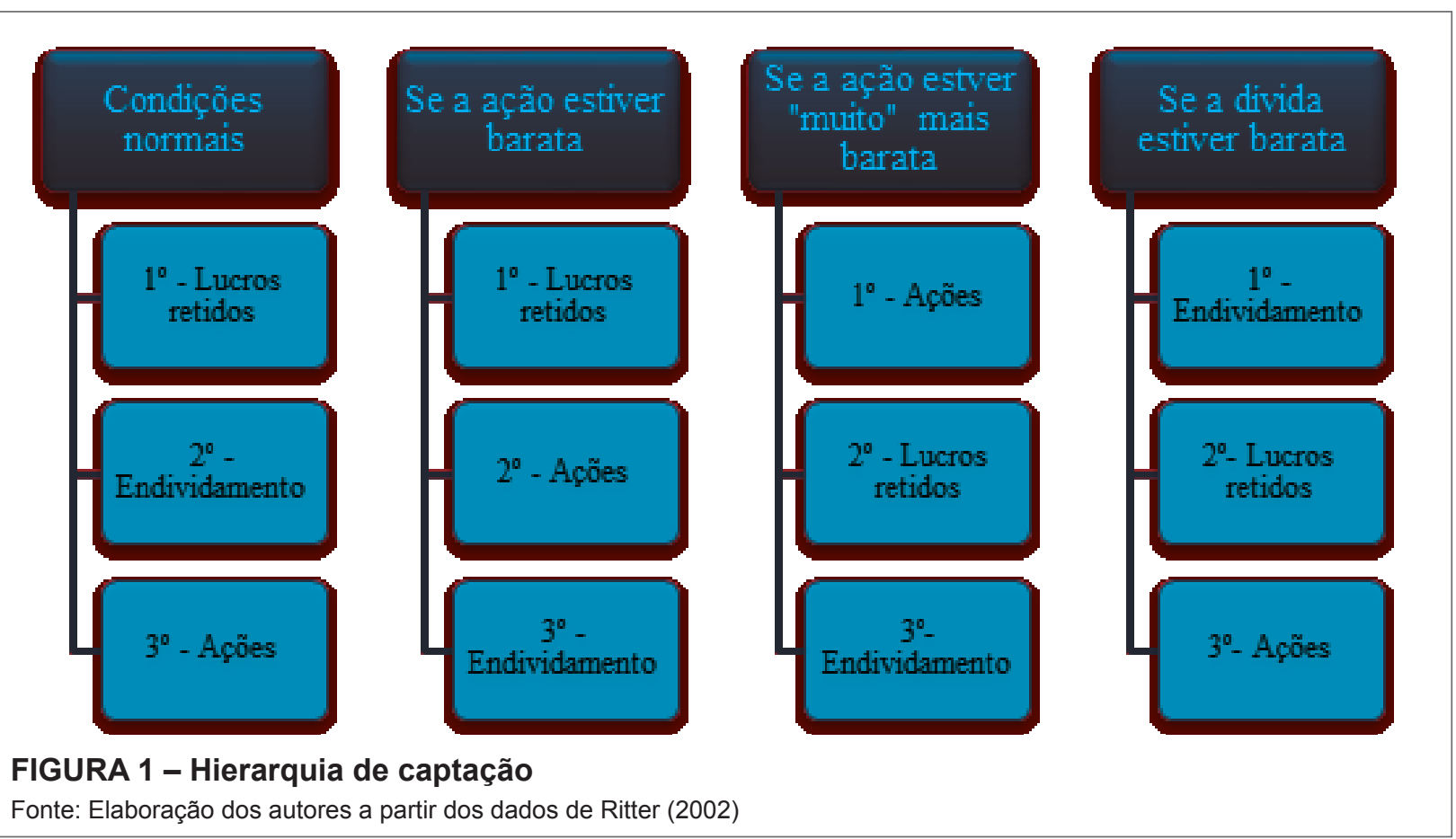

No Brasil, Eid Júnior (1996) concluiu que $47 \%$ das empresas seguem a ideia de captar recursos no momento em que é mais proveitoso economicamente, utilizando assim o oportunismo como determinante da estrutura de capital. Já Santos, Pimenta Junior e Coccini (2009) também analisaram os determinantes da estrutura de capital no Brasil, tendo observado que $13 \%$ da sua amostra apresentaram a mesma ideia do oportunismo. Gimenes, Opazo e Gimenes (2003) analisaram cooperativas e verificaram que o oportunismo determina a estrutura de capital de 64,29\% de sua amostra. Os trabalhos de Aguirre (20II) e de Matsuo (2004) também discorrem sobre pontos relacionados ao oportunismo, contudo vale salientar que os mesmos são resultado de pesquisas de trabalhos de conclusão de curso de especialização e de dissertação, respectivamente.

É importante destacar que no Brasil o número de estudos que levam em consideração o oportunismo na estrutura de capi- tal, ainda, é pequeno. Não sendo encontrados estudos que possuem como principal temática a indústria de nanotecnologia e estrutura de capital.

\section{EBT DE NANOTECNOLOGIA E AS FORMAS DE FINANCIAMENTO}

A maioria das empresas de nanotecnologia podem ser consideradas empresas de base tecnológica (EBT), uma vez que, de acordo com Kadji e Filion (2002), tais empresas são organizações que têm origem a partir de tecnologias desenvolvidas, principalmente, no interior da organização de onde se originam, podendo ser um centro de pesquisa, uma empresa privada ou uma universidade. Nessas empresas as primeiras vendas são realizadas aproximadamente um ano após sua criação, visto que precisam de um tempo para desenvolverem a pesquisa, criar o produto e colocá-lo em comercialização.

Segundo Toma e Araki (2005), "nano" significa "anão", em grego, sendo um pre- 
fixo usado na notação científica utilizado para expressar um bilionésimo, , ou seja, um bilionésimo de metro.As empresas que atuam neste mercado possuem o entendimento e o controle de matérias e processos em escala manométrica.

Para se financiar, como qualquer outra empresa, as EBT's possuem à sua disposição diversas fontes de financiamento, que podem compor sua estrutura de capital.Além dos recursos de origem do capital próprio, como lucros retidos, ações, commercial paper, american depositary receipt (ADR), reservas legais e operações de factoring, tem-se também os recursos de terceiros, tais como operações de leasing, debêntures empréstimos e financiamentos (GITMAN, 2004; CHEROBIM, 2008;ASSAF NETO, 20I0).

No caso do financiamento, é importante informar que, no Brasil, tem-se uma modalidade denominada não reembolsável. Ela é concedida a instituições científicas e tecnológicas nacionais, podendo ser públicas ou privadas, para executarem projetos de desenvolvimento científico e tecnológico, de infra-estrutura de pesquisa, bem como de capacitação de recursos humanos. Neste caso a empresa adquiri o recurso financeiro, tendo ou não que oferecer uma contrapartida, e não precisa devolver o recurso ao credor. Entende-se que o retorno será o oferecimento de produtos ou serviços à sociedade, contribuindo para o desenvolvimento econômico do país (FINEP, 20I6).

Além dos recursos de terceiros mencionados têm-se também outras modalidades que buscam ajudar no desenvolvimento de negócios, dentre eles pode-se citar: a) seed money, um recurso direcionado para empresas que se encontram no estágio inicial e são destinados para a avaliação da viabilidade técnica do negócio; b) angels, um indi- víduo ou um grupo de pessoas que possui recursos financeiros e pretende investir em novas empresas, não cotadas na bolsa; c) venture capital, um tipo de investimento de origem privado, por meio do qual se adquire participação societária em empresas que apresentem possibilidades de crescimento, nessa modalidade os investidores participam diretamente dos riscos e da alavancagem do negócio, agregando valor com base em orientação administrativa, comercial e financeira; e d) private equity, que possuem uma estrutura semelhante aos fundos de venture capital, contudo realizam o investimento de um volume maior de recursos financeiros e em diversos casos, o intuito desta modalidade é levar a empresa a abrir capital (MEIRELLES; PIMENTA JR.; REBELATTO, 2008; FRICK; SALES; FRICK, 20I0).

\section{METODOLOGIA}

A presente pesquisa é de natureza descritiva qualitativa.A mesma foi desenvolvida através do método de estudo de caso em uma empresa, por meio de entrevistas semi-estruturadas com o gestor responsável pelos assuntos relacionados ao tema em análise. Os dados coletados foram analisados através da técnica de análise de conteúdo. Devido a questões de confidencialidade o nome da empresa e do gestor não foram divulgados, assim, denominou-se, respectivamente, de Alfa e AI. A escolha da empresa se deu por acessibilidade aos dados.

As entrevistas, gravadas, foram conduzidas abordando aspectos gerais da empresa, a estrutura de capital, os determinantes de tal estrutura e a relevância de algumas fontes.Vale ressaltar que além da verificação da utilização da ideia do oportunismo foi analisada a utilização de outros determinantes, tais como o trade off e a teoria de pecking 
order, buscando confirmar ou refutar a ideia do oportunismo como determinante.Ainda, na busca pela confirmação das informações, foi abordado a relevância de algumas fontes de financiamento com o objetivo de cruzar tais aspectos com as informações sobre a estrutura de capital e seus determinantes.

Durante o desenvolvimento da pesquisa deparou-se com a seguinte limitação, as empresas que fazem parte do escopo analisado (EBT de nanotecnologia de capital fechado), geralmente, possuem um número reduzido de colaboradores e uma estrutura enxuta, sendo assim, tem-se apenas um responsável pelo tema abordado, o que se torna uma limitação ao se falar de um estudo de caso. Contudo, optou-se por desenvolver o estudo, mesmo diante da presente limitação, uma vez que se acredita que as contribuições advindas desse trabalho contribuem para o desenvolvimento do conhecimento nesta área, ajudando a preencher as lacunas existentes.

\section{ESTUDO DE CASO}

A empresa Alfa surgiu em 2009 e possuía três sócios. Em 20I I, ao ganhar um projeto do Conselho Nacional de Desenvolvimento Científico e Tecnológico (CNPQ), aumentou seu número de colaboradores e passou a ter em seu quadro 8 profissionais. Até a data da primeira entrevista, a Alfa possuía três sócios e seis colaboradores. Sendo que destes três sócios, apenas, um atua na empresa com o cargo de diretor.

A sede da empresa se encontra na região Sul do Brasil, onde estão localizadas as áreas de logística, comercial, laboratório e marketing. A Alfa realiza a pesquisa, produz alguns gramas e terceiriza a produção em grande escala, realizada em São Paulo.

Apesar de ter sido criada em 2009, a Alfa passou a comercializar seus produtos em 2013, devido a necessidade de um certo tempo, entre sua criação e comercialização de produtos/serviços, para desenvolver a pesquisa e o produto. A Figura 2 ilustra as etapas percorridas pela empresa até o momento de comercializar seu produto.

A Alfa levou aproximadamente quatro anos para começar a gerar receita. Porém, os gastos totais tiveram início logo no co-

- Desenvolvim ento;

- Aum ento de escala;

- Validação de fornecedores, m atéria prim a e rotulo.

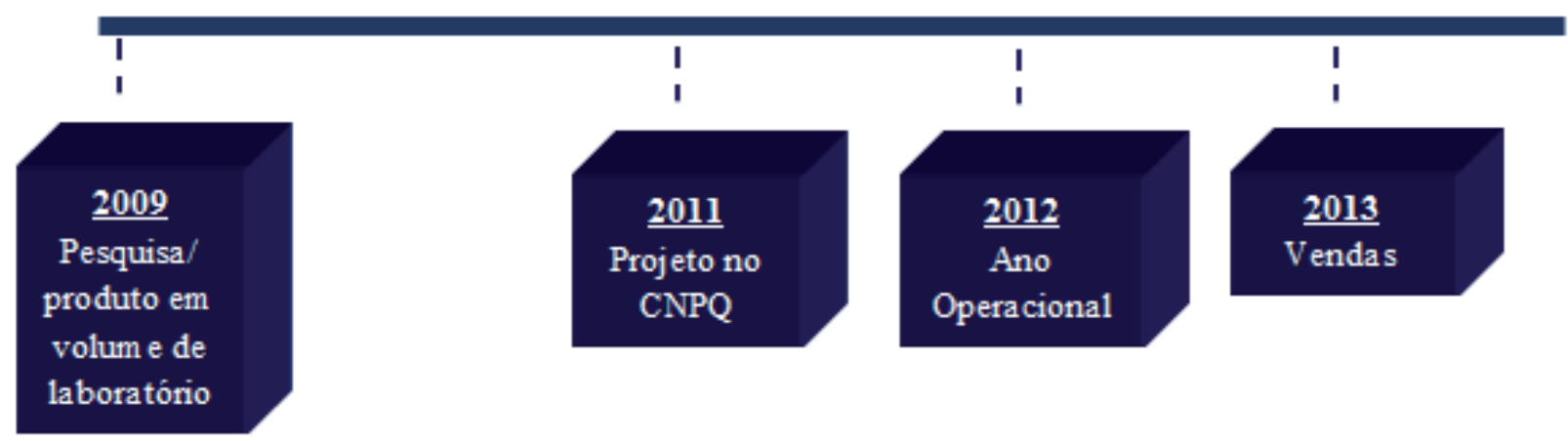

FIGURA 2 - Linha do tempo da empresa Alfa

Fonte: Elaborada pelos autores, 2015. 
meço da pesquisa. Para se financiar, a empresa utilizou recursos financeiros gerados pela conquista de prêmios e investimentos do governo na modalidade de financiamento não reembolsável. Após o término desses recursos financeiros, os sócios se reuniram e realizaram aportes financeiros.

Nos dois primeiros anos, a Alfa se financiou completamente com investimento a financiamento não reembolsável. No terceiro ano, $60 \%$ dos recursos vieram do financiamento não reembolsável, o restante veio dos sócios que realizaram um aporte de aproximadamente $40 \%$ dos recursos financeiros necessários para a operacionalização da empresa.

Nos anos seguintes, a empresa financiou suas atividades com aproximadamente $80 \%$ dos recursos originados do seu faturamento e $20 \%$ dos sócios.

Com a estrutura apresentada na Tabela I é possível verificar que ao longo dos anos a mesma sofre alterações, que são realizadas de acordo com a oportunidade de cada momento, apresentando assim indícios da ideia do oportunismo.

Durante a pesquisa, o entrevistado Al foi questionado sobre a existência de uma estrutura meta de capital, assim como de uma hierarquia das fontes de financiamento. Além de tais pontos foram abordados aspectos relacionados aos motivos pelos quais uma fonte é preterida em relação à outra e como as mesmas são escolhidas. Alguns destes pontos refletem diretamente aos determinantes, que refletem alguma teoria de estrutura de capital, apresentados no Quadro I, juntamente com a fala do entrevistado.

Diante das informações apresentadas é possível observar que a empresa não possui uma estrutura de capital determinada. Ao questionar $\mathrm{Al}$ sobre uma hierarquia das fontes de financiamento, o entrevistado determina uma ordem, conforme Figura 3.

Em primeiro lugar vem o capital próprio (geração interna); em segundo, o capital de terceiros (financiamento não reembolsável); em terceiro, o capital próprio (recursos dos sócios); e em quarto, o capital próprio (abrir capital). Ao comparar a hierarquia das fontes de financiamento da Alfa com a teoria de pecking order, em que a preferência das fontes é apresentada também na Figura 3, é possível observar que existem pontos semelhantes, como é o caso da primeira e da última opção. Porém, a hierarquia adotada diverge da apresentada pela teoria de pecking order.

Tal hierarquia não é inflexível, ela pode mudar a qualquer momento devido as mudanças de cenário e dos custos de tais fontes.

Vale ressaltar que a determinação da hierarquia, apresentada por AI, se dá a partir do conhecimento tácito que o gestor possuiu sobre o assunto, após analisar as

TABELA 1 - Composição do capital da empresa Alfa

\begin{tabular}{c|c|c}
\hline Ano & Capital próprio (em \%) & Capital de terceiros (em \%) \\
\hline $\mathbf{2 0 0 9}$ & 0 & 100 - financiamento não reembolsável \\
\hline $\mathbf{2 0 1 0}$ & 0 & 100 - financiamento não reembolsável \\
\hline $\mathbf{2 0 1 1}$ & 40 & 60 - financiamento não reembolsável \\
\hline $\mathbf{2 0 1 2}$ & 100 & 0 \\
\hline $\mathbf{2 0 1 3}$ & 100 & 0 \\
\hline $\mathbf{2 0 1 4}$ & 100 & 0 \\
\hline
\end{tabular}

Fonte: Elaborado pelos autores, 2015. 
QUADRO 1 - Determinantes da estrutura de capital.

\begin{tabular}{|l|l|}
\hline \multicolumn{2}{|l|}{ TEORIA DE ESTRUTURA DE CAPITAL } \\
\hline $\begin{array}{l}\text { Estrutura meta } \\
\text { de capital }\end{array}$ & $\begin{array}{l}\text { Hoje, nós não temos nenhum planejamento nesta área, neste tema, neste conceito, basicamente. Temos } \\
\text { dinheiro de prêmios e projetos [...]. [...] Então, como que funciona? Nós não temos nada estipulado. O que } \\
\text { nós não gostaríamos é ter de colocar o dinheiro de casa; ou seja, fazer novos aportes [...] (A1). }\end{array}$ \\
\hline \multirow{3}{*}{ Hierarquia } & $\begin{array}{l}{[\ldots] \text { abrir capital. Se existe uma hierarquia, ela é a última. Já recebemos três convites. Não abrimos ne- }} \\
\text { nhum deles. Primeiro de tudo, é fundo perdido'. Tudo que vem de fundo perdido e prêmio e contrapartida } \\
\text { abaixo de 10\% a gente tá escrevendo, tá indo atrás. Nós identificamos que isto é uma das únicas poucas } \\
\text { maneiras que você tem para rever a quantidade de imposto exorbitante que a gente paga no país. Então, } \\
\text { assim, a gente teoricamente, não reclama dos impostos por ter benefícios de projetos de subvenção. } \\
\text { Estas são as prioridades. A parte de abertura de capital, ela está bem longe, porque eu tenho dois sócios } \\
\text { bastante fortes. Caso seja necessário, eles aumentariam a participação da empresa e bancariam por mais } \\
\text { um tempo a empresa (A1). }\end{array}$ \\
\hline $\begin{array}{l}\text { Geralmente é. Geralmente é isto, porque como você trabalha com projetos inovadores. Agora, por exem- } \\
\text { plo, a gente ganhou o prêmio do CNN. O que nos favorece? Caso você queira financiamento, a carência } \\
\text { é maior, os juros são menores. Daí, por ter algumas facilidades, a gente começa a olhar a possibilidade } \\
\text { de ter financiamento privado [...]. Tudo decidido de acordo com o momento. Nesta época de eleições, por } \\
\text { exemplo, ninguém fez nada. Nós ficamos praticamente parados. Vai do momento, vai da oportunidade. } \\
\text { Você falou oportunismo (A1). }\end{array}$ \\
\hline
\end{tabular}

Fonte: Elaborado pelos autores, 2015

${ }^{1} \mathrm{O}$ termo fundo perdido é a considerado financiamento não reembolsável.
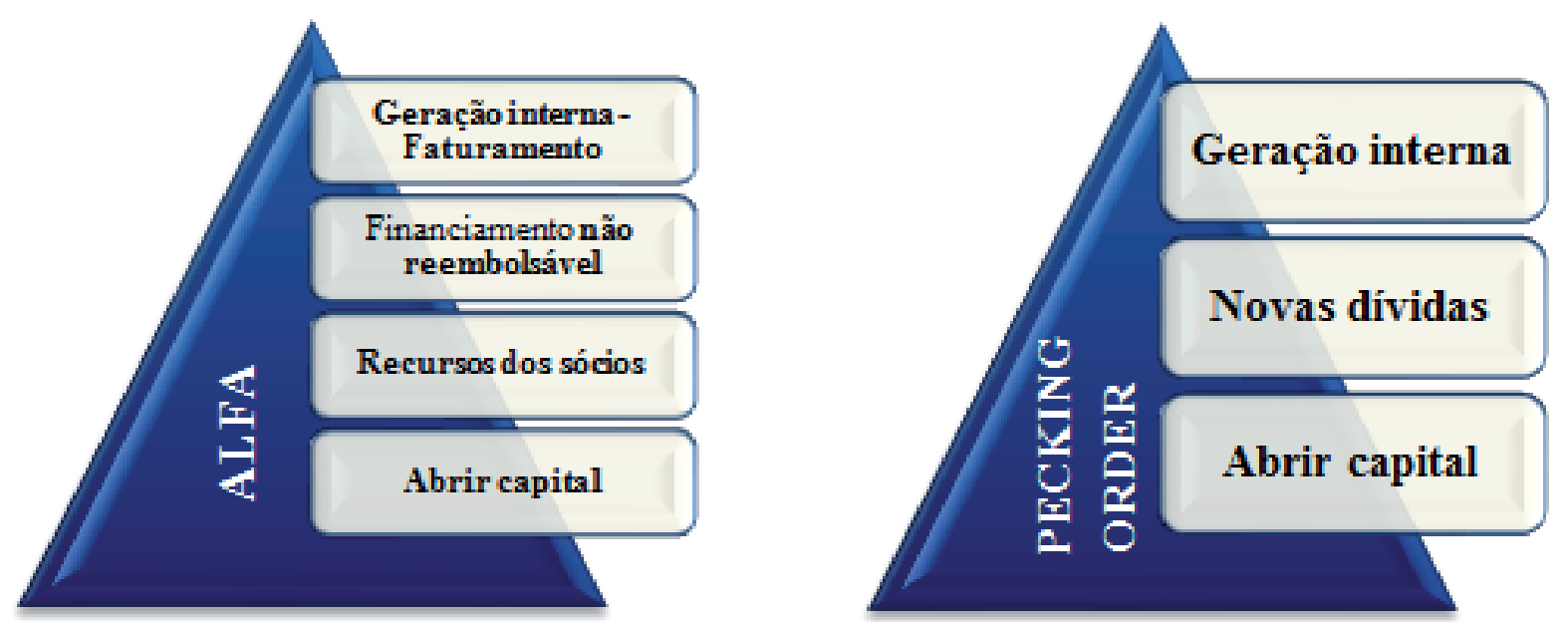

FIGURA 3 - Comparação da Hierarquia das fontes de financiamento da Alfa com a teoria de peking order

Fonte: Elaborado pela autora, 2015.

fontes de financiamento à disposição de sua empresa juntamente com as questões relacionadas ao custo e exigências.

[...] A gente calcula bem os riscos ali referentes à inovação. Inclusive, hoje eu dei uma entrevista para uma revista do RS sobre este tema. Ele:Ah como você financia tua inovação? Aí, eu: Ah tudo tem um risco, e a gente calcula bem este risco para ver quando isto pode se tornar um retorno para empresa ou não, e não utiliza capital de terceiros, utiliza capital próprio (AI).

Apesar da informação de não utilização de capital de terceiros em sua estrutura, 
foi observado que a Alfa já foi contemplada sete vezes por recursos do governo, na modalidade não reembolsável, o que contribuiu para o desenvolvimento da empresa nos primeiros estágios. Vale destacar que tais recursos são vistos pelos sócios como sendo interessantes pelo seu custo e também pela facilidade de obtenção do mesmo.

[...] Nós temos recursos humanos de alta competência. Tem doutor, mestre, pós-doc. Tem de tudo na empresa. Então, assim, nós aprendemos e temos um grupo de pessoas só para escrever. Não só para escrever, mas para identificar e aumentar a taxa de sucesso dos projetos que nós escrevemos. Então, assim, o dinheiro tá ali e só não pega quem não quer. Então, a ideia é aproveitar a oportunidade. Tem o dinheiro ali, vamos pegar o dinheiro (AI).

Ainda em relação aos recursos não reembolsáveis, é possível observar mais indícios da ideia do oportunismo, visto que quando tal recurso está disponível no mercado a empresa Alfa busca utilizar o mesmo, ou seja, se ele é uma oportunidade disponível para a empresa, a mesma irá buscar incluir tal fonte em sua estrutura de capital.

$\mathrm{Na}$ Tabela I, onde foi apresenta a estrutura de capital da Alfa, é possível observar que as fontes mais utilizadas foram recursos próprios (faturamento e sócios) e recursos de terceiros (financiamento não reembolsável), o que também é confirmado na hierarquia das fontes. Porém é importante mencionar que esta estrutura se deu não pelo fato da empresa não possuir acesso a outras fontes de financiamento, pois os sócios realizam comparações entre a remuneração exigida pelos sócios e a exigida por terceiro. Porém, a remuneração exigida por terceiros não agrada aos sócios, que preferem continuar com capital próprio e, quando possível, financiamento não reembolsável.

[...] a gente tem acesso, por exemplo, ao Badesc e outras fontes de financiamento pelo FINEP, mas, poxa, toda vez que a gente vai avaliar a gente "Não, não, não vamos fazer isto. Vamos segurar". A gente só faz aquela comparação e vê ali os juros sobre juros mensal, que vai dar no pacote lá no final do ano. "Ah pô.Vamos tentar mais uns seis meses. Vamos tentar mais um tempo com capital próprio". Enfim, e daí vai. Mas esta comparação agora para eu te falar, "Ah fizeram?" Não, essa comparação foi a seguinte: a gente abriu a tabela do banco e viu ali os juros, e:"Pô! Vamos fazer capital próprio" (AI).

Questionado sobre a utilização de recursos originados pelos venture capital e private equity, $\mathrm{Al}$ mencionou que a Alfa já recebeu convite de alguns fundos de investimentos, contudo optou por não aceitar. Questionado sobre o motivo da não aceitação,Al respondeu:

[...] é estratégia. Justamente porque nós não queremos ficar reféns de grupos de investimento. Então, você tem uma taxa de crescimento pouco mais baixa de empresas que foram aportadas, porém você tem toda a segurança da empresa na sua mão. Justamente estratégia, porque quando você abre o capital você perde o controle da empresa. Você está suscetível às contratações e decisões do grupo, sem falar do que em três ou quatro anos lá eles tiram as mes- 
mas cotas que eles compraram por dois milhões por dez milhões. Ou seja, você não vai conseguir comprar e vai ter empecilho, uma pessoa ali te pondo a faca no peito sempre. Esta é a principal justificativa que a gente utiliza para não abrir capital (Al).

Como é possível observar, a Alfa não percebe vantagens em um investidor externo (venture capital e private equity) e prefere continuar com o número de sócios que já possui e a se financiar da forma que já vem sendo feita, mesmo tendo uma taxa de crescimento menor que as empresas aportadas. Afirma Al: “Ele vai lá, com uma negociação leva 20, 25\% da tua empresa, e isto é, nossa, muito mais caro do que qualquer financiamento[...]".

Em relação a relevância de algumas fontes de financiamento, o Quadro 2 apresenta o relato de $A$ I sobre as mesmas. Foi questionado caso a empresa não tivesse utilizado tal recurso como a mesma teria se desenvolvido.

É possível observar que tanto os recursos dos sócios quanto os recursos de financiamento não reembolsável são relevantes para a empresa Alfa. Diferente dos recursos originados pelos bancos, que é visto, por Al, como uma fonte não interessante para Alfa. $O$ que já foi apresentado, através da ausência de tal fonte, na Tabela I e na Figura 3.

Ao se cruzar algumas das informações apresentadas é possível, novamente, confirmar a irrelevância dos bancos como fonte e financiamento e a relevância dos recursos próprios e dos recursos não reembolsável, conforme Quadro 3.

É possível observar que a relevância (ou não) das fontes de financiamento está diretamente ligada ao custo e exigências que as mesmas possuem. Assim, Al acaba utilizando da ideia do oportunismo durante as análises referentes a tomada de decisão sobre a estrutura de capital que será adotada. Isto pode ser comprovado nas falas do entrevistado, que apresentam informações sobre análises envolvendo a necessidade e possibilidades de assumir obrigações, por parte da empresa, advindas da adoção de determinada fonte de financiamento, assim

QUADRO 2 - Relevância das fontes de financiamento

\begin{tabular}{|l|l|}
\hline Recurso & Empresa Alfa \\
\hline Sócios & O desenvolvimento seria mais lento \\
\hline Bancos & $\begin{array}{l}\text { Não existiria, pois se isto fosse feito no momento errado, nós quebraríamos, porque não ia ter capi- } \\
\text { tal para bancar o investimento, para pagar o banco. }\end{array}$ \\
\hline $\begin{array}{l}\text { Financiamento não } \\
\text { reembolsável }\end{array}$ & Não teria nem existido \\
\hline
\end{tabular}

Fonte: Elaboração dos próprios autores, 2015

QUADRO 3 - Cruzamento das informações sobre as fontes de financiamento

\begin{tabular}{|l|c|c|c|}
\hline Recurso & $\begin{array}{c}\text { Consta na } \\
\text { estrutura de capital }\end{array}$ & $\begin{array}{c}\text { Ordem na } \\
\text { hierarquia }\end{array}$ & É relevante \\
\hline Recurso próprio - Faturamento & $\operatorname{Sim}$ & $1^{\circ}$ & Relevante \\
\hline Recurso próprio - Sócios & $\operatorname{Sim}$ & $3^{\circ}$ & Relevante \\
\hline $\begin{array}{l}\text { Recurso de terceiros - recursos não } \\
\text { reembolsável }\end{array}$ & $\operatorname{Sim}$ & $2^{\circ}$ & Relevante \\
\hline Recurso de terceiros - Banco & Não & Não possui & Não relevante \\
\hline
\end{tabular}

Fonte: Elaborado pelos autores, 2015 
como o custo que as fontes disponíveis no mercado possuem.

\section{CONSIDERAÇÕES FINAIS}

Diante da característica da empresa analisada e do cenário que a mesma se encontra, é possível inferir que a ideia do oportunismo é a determinante que defini a estrutura de capital levando em consideração as demais teorias analisadas.

O gestor demonstrou que as fontes para financiar as atividades da empresa Alfa são escolhidas levando em consideração, principalmente, o valor que a empresa deverá pagar por utilizar tal fonte, assim como as exigências feitas pelo credor, que em vários casos não interessam aos sócios, motivo pelo qual a mesma não possui em sua estrutura recursos originados de fundos de venture capital e private equity. Desta forma, caso apareça uma fonte com menor custo e exigências, que são compreendidas como sendo interessantes para a empresa, os gestores não possuem resistência em alterar a estrutura vigente.

Diferente dos trabalhos realizados por outros autores, a presente pesquisa proporcionou, através das falas do entrevistado, uma análise mais profunda sobre o tema. Uma vez que foi possível apresentar informações mais detalhadas sobre aspectos relacionados as fontes de financiamento que se encontram à disposição de sua empresa e que influência na adoção ou não de tais fontes na estrutura de capital.

Como sugestão de pesquisa futura aponta-se a realização de um estudo que avalie outras empresas de segmentos distintos do apresentado, para que se possa ser feito uma análise que busque verificar se as características relacionadas a empresa e ao segmento exercem alguma influência no determinante da estrutura de capital. 
AGUIRRE, J. R. Estrutura de capital e a forma de financiamento de pequenas empresas que fazem parte da carteira do banco do Brasil. $201 \mathrm{I}$. 54 f. Trabalho de conclusão de curso (Especialização em Gestão de Negócios Financeiros) - Escola de Administração, Universidade Federal do Rio Grande do Sul, Rio Grande do Sul, 201 I.

ASSAF NETO,A. Finanças Corporativas eValor. 3. ed. São Paulo:Atlas. 2010.

BAKER, M.; GREENWOOD, R.;WURGLER, J. The maturity of debt issues and predictable variation in bond returns. Journal of Financial Economics forthcoming, 2002.

BOSSE, D. A. Bundling governance mechanisms to efficiently organize small firm loans. Journal of Business Venturing, v. 24, p. 183-195, 2009.

CHEROBIM, A. P. M. S. Estrutura de Capital: Revisão Teórica. In: SAlTO, R. PROCIANOY, J. L. Captação de Recursos de Longo Prazo, São Paulo:Atlas, 2008.

DEANGELO, H.; MASULIS, R. W. Optimal Capital Structure Under Corporate and Personal Taxation. Journal of Financial Economics. v. 8, n. I, p. 3-29, 1980.

DURAND, D. Cost of debt and equity funds for business: trends and problems of measurement. In: conference on research on business finance, 1952.

EID Jr,W. Custo e estrutura de capital: o comportamento das empresas brasileiras. Revista de Administração de Empresas, São Paulo, v. 36, n. 4, p. 5 I-59, 1996.

FINEP. Financiadora de Estudos e Projetos - Disponível em: http://www. finep.gov.br/pagina.asp?pag=financiamento_modalidades. Acesso em 30 mar. 2016.

FRICK, T. F S.; SALES, I. D.; FRICK, O.
O.Financiamento de Capital Empreendedor para ENBTs: O Caso das Empresas Incubadas na Incamp,2010. Disponível em <http:// www.stratangels.com.br/>. Acesso em 18 nov. 2015.

GIMENES, R. M. T.; OPAZO, M. A. U.; GIMENES, F. M. P. Como decidem os executivos financeiros sobre estrutura de capital em cooperativas agropecuárias. Revista de Ciências da Administração, v.5, n.09, jan/jul, 2003.

GITMAN, L. J. Princípios de administração financeira. 10. ed. São Paulo: Pearson, 2004.

GRAHAN, J. R.; HARVEY, C. R. The theory and practice of corporate finance: evidence from the field. Journal of Financial Economics, v. 60, p. I87-243, 200 I.

JENSEN, M. C.; MECKLING, W. H. Theory of the firm: managerial behavior, agency cost and ownership structure. Journal of Financial Economics. v.3, p. 305-360, 1976.

JONES, O.; JAYAWARNA, D. Resourcing new businesses: social networks, bootstrapping and firm performance. Venture Capital, v. 12 , n. 2, p. I27-I52, 2010.

KADJI-Y. C.; FILION, L. J. Essaimage technologique. Examen de la documentation. Cahier de recherché. Chaire d'entrepreneuriat RogersJ.-A. Bombardier, HEC Montréal. 2002.

KJELLMAN,A.; HANSÉN, S. Determinants of capital structure: theory vs. practice. Scandinavian Journal of Management. v. II, n. 2, p. 91-102, 1995.

MATSUO, A. K. Oportunismo em estrutura de capital: evidências do Brasil no período 1994-2003. 2004. I26f. Dissertação (Mestrado em Administração) - Escola de Administração de São Paulo, Fundação Getú- lio Vargas, São Paulo, 2004.

MEIRELLES, J. L. F.; PIMENTA JR., T.; REBELATTO, D. A. N. Venture capital e private equity no Brasil: alternativa de financiamento para empresas de base tecnológica. Gestão e Produção, v. I5, n. I, p. I I2I, 2008.

MILLER, M. H. Debt and taxes. The Journal of Finance. v. 32, n. 2, p. 26 I275, 1977.

MODIGLIANI, F.; MILLER, M. H. The cost of capital, corporation finance, and the theory of investiment. The American Economic Review. v. 48, n. 3, p. 26I-297, I 958.

MODIGLIANI, F.; MILLER, M. H. Dividend policy, growth and the valuation of shares. Journal of Business. v. 34, n. 4, p. 4I I-433, I 96 I.

MODIGLIANI, F.; MILLER, M. H. Corporate income taxes and the cost of capital: a correction. American Economic Review. v. 53, n. 3, p. 433443, 1963.

MYERS, S. The capital structure puzzle. The Journal of Finance. v. 39, n. 3, p. 575-592, 1984.

MYERS, S C.; MAJLUF, N S. Corporate Financing and Investment Decisions When Firms Have Information Investors Do Not Have, Journal of Financial Economics. v. I3, p. 187-222, 1984.

PINEGAR, M. J.;WILBRICHT, L. What managers think of capital structure theory: a survey. Financial Management, Oxford, v.4, n.18, p.8291, 1989.

RITTER, J. R. The windows of opportunity theory of capital structure. In: Encontro Brasileiro de Finanças, II, Rio de Janeiro, 2002.

SANTOS, C. M.; PIMENTA JUNIOR, T.; CICCONI, E. G. Determinantes da escolha da estrutura de capital das empresas brasileiras de capital aberto: um survey. Revista de Ad- 
ministração da Universidade de São SILVA, D. F.A. O Impacto do Corporate Paulo, São Paulo, v.44, n. I, p.70-8I, jan./fev./mar. 2009.

SCOTT Jr., D. F. e MARTIN, J.D. Indus-

try Influence on Financial Structure, Financial Management, v. 4, p. $67-73,1976$. Governance na Estrutura de Capitais, 2009, 138 p.Tese de Mestrado em Finanças. Faculdade de Economia. Universidade do Porto. Portugal, 2009.

TOMA, H. E.; ARAKI, K. Nanociência e Nanotecnologia. Ciência Hoje. v. 37, n. 217, 2005.

WILLIAMSON, O. E. TransactionCost Economics:The Governance of Contractual Relations. Journal of Law and Economics, s.l. : s.n., XXII, , p.233- 26I, October. 1979. 